\title{
VII. Description of an improved gauge for ascertaining with precision the pressure of highly compressed steam, gases, and fluid bodies
}

\section{Mr. Samuel Seaward}

To cite this article: Mr. Samuel Seaward (1824) VII. Description of an improved gauge for ascertaining with precision the pressure of highly compressed steam, gases, and fluid bodies, Philosophical Magazine Series 1, 63:309, 36-40, DOI: 10.1080/14786442408644460

To link to this article: http://dx.doi.org/10.1080/14786442408644460

曲 Published online: 29 Jul 2009.

Submit your article to this journal $\pi$

ЏII Article views: 2

Q View related articles $\sqsubset$ 
mica, of which there are some small plates interposed, even in the substance of the girasol. This gangue contains, in the interior of its substance, a considerable quantity of pale-blue crystallized spinelle, among which, however, there are some crystals of so deep a blue that they appear black. M. Leschenault only found this rock on the bank of a river seven miles to the north-east of Candy, on the route to the province of Fassagram, where he met with it in isolated masses.

The sixth gangue of Ceylon spinelle, which is still more particular, is a rock of a granitic aspect, in which the mica is replaced by molybdena in small thin laminæ. This rock is principally composed of transparent granular felspar, and of these laminæ of molybdena. One may observe, besides, some little plates of brown mica, which are thinly disseminated, and a great number of very pale-red crystals of spinelle. This rock was found by $M$. Leschenault, seven miles to the north-east of Candy, in the same district as the preceding, and likewise in isolated masses upon the bank of the same river.

I may add to the description of these gangues of spinelle, that of a seventh, which is the second of those I have described in the paper on Corundum, printed in the Philosophical Transactions for 1802. This gangue consists principally of transparent felspar or adularia, pure in one part, and mixed in the other with magnetic pyrites and a little carbonate of lime. Some small crystals of spinelle are disseminated in it, but more thinly than in the other gangue mentioned in the same memoir.

VII. Description of an improved Gauge for ascertaining with Precision the Pressure of highly compressed Steam, Gases, and Fluid Bodies. By Mr. Samuer Seaward.

\section{To the Editors of the Philosophical Magazine and Journal.}

Gentlemen,

DERMIT me to offer you the accompanying description of a gauge for measuring the pressure of highly compressed fluids or gases, which I shall feel gratified by your introducing into your valuable Magazine, if you consider it deserving of that distinction.

$$
\text { I am, gentlemen, yours, \&c. }
$$

3 Charles Street, City Road, Jan. 14, 1824 .

Samuel Seaward. 


\section{Description, \&c.}

Considerable difficulty has been experienced in acertaining in a satisfactory manner the exact pressure of highly condensed gases or fluids.

The usual method of accomplishing this object is by the rising of a column of mercury in a glass tube hermetically sealed at the top; the tube being previously filled with air at the ordinary pressure of the atmosphere. For as the mercury rises by the pressure of the gas, the air confined in the tube above the surface of the mercury will be compressed to the same degree as the gas itself, making proper allowance for the weight of the column of mercury. But it happens that when fluids are required to be compressed to 30 or 40 atmospheres, it becomes necessary to have the tube of the mercury gauge of very great length, say from 30 to 45 feet, otherwise the divisions of the upper part of the scale will be much too small for useful reference; but this great length renders the apparatus exceedingly inconvenient for practical purposes.

The accompanying drawing represents a gauge on an improved principle, which it is expected will be found much more convenient and correct than the gauge in common use. The gauge consists of two small cylindrical chambers $\mathrm{A}$ and $\mathrm{B}$, and the glass tube $\mathrm{C}$. 'The communication between the two is by the small tube $d$, which reaches nearly to the bottom of the lower chamber.

The glass tube $\mathrm{C}$ we will suppose to be about eight feet long: the chamber $\mathrm{B}$ is to be filled with mercury as high as the line $c c$; the tube $e$ is to admit the compressed gas or fluid, which acting on the surface of the mercury forces it up the tube $d$, which after filling the chamber A will rise in the tube $\mathbf{C}$.

Now, supposing the apparatus to be previously filled with air of the common atmospheric pressure, and that the chamber $\mathbf{A}$ be equal to 19 times the capacity of the

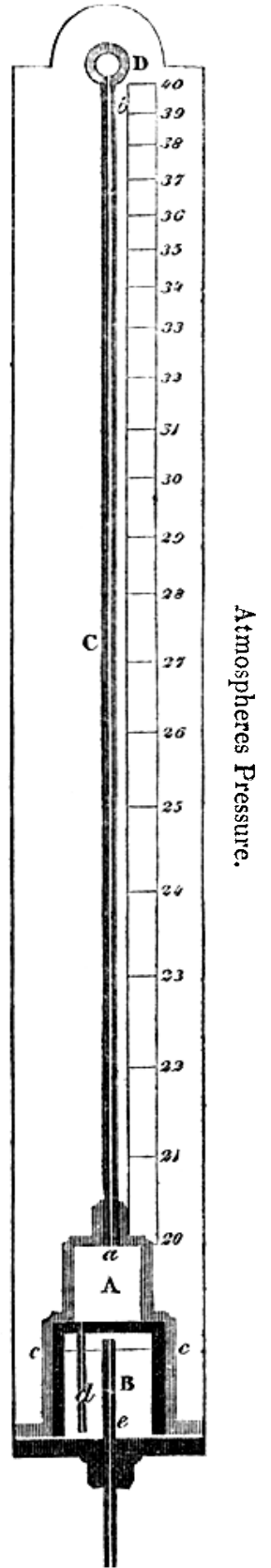

tube 
tube $c$; it is quite plain, that when the mercury is forced by the pressure of the gas or fluid into the chamber $A$, and rises up to the bottom of the glass tube, the air in the tube $\mathrm{C}$ must then be compressed 20 times, and will consequently indicate a pressure of 20 atmospheres; and if the mercury is then raised half way up the tube $\mathrm{C}$, the air will then be compressed 40 times, and will indicate a pressure of 40 atmospheres. We have considered that the glass tube $\mathrm{C}$ should be eight feet long; but if, instead of eight feet, we make this tube only four feet long, and fix to the top a small hollow ball $D$, of equal capacity with four feet of the tube; then if the mercury rise four feet high in the tube, or up to the ball, the apparatus will still indicate a pressure of 40 atmospheres, as if the tube eight feet long had been employed.

By this means we have a compact instrument, which will indicate in a satisfactory manner the various pressures within the range of 20 and 40 atmospheres; for the divisions on the scale for the whole of this range will be as large as if a tube of the common form 70 feet long had been employed.

But it may be objected that this instrument is imperfect, because it will not indicate any lower pressure than 20 atmospheres, nor any higher than 40. To this it should be observed, that in all practical applications of a gauge of this sort, as the compression of gases, \&c., it is only within certain limits that it is desirable to ascertain the exact pressure: for instance, in the case alluded to, it is of no consequence to ascertain the pressure when below 20 atmospheres; nor is it ever required to be elevated above 32 atmospheres; therefore a range, as here proposed, of from 20 to 40 atmospheres is quite sufficient for practical purposes in working the apparatus of a portable gas establishment, \&c. Perhaps it is unnecessary to observe, that the various ranges may be altered at pleasure, from the lowest pressure up to the greatest; for by properly arranging the different sizes of the ball $\mathrm{D}$ and chamber $A$, it may be made to indicate from 1 to 20 -from 20 to $40-$ from 40 to 60 , and 60 to 100 atmospheres. And if it should ever happen to be necessary to ascertain the exact pressure of the fluids from 1 atmosphere to 100, which is a thing perhaps never wanted, it can still be done with the same degree of exactness throughout; for, by using two or more of these ganges graduated for different ranges, we thus obtain a correct scale of reference, which it would be impossible to do in the old method; say from 1 to $15-15$ to $45-$ and 4.5 to 100 .

It is here proper to observe, that the weight of the column of mercury in the chamber $A$, and in the tube $C$, should be taken 
for the Pressure of highly compressed Steam, Gases, \&c. 39

taken into account as well as the pressure of the air in the tube $\mathrm{C}$; otherwise it will not be a correct indication of the force of the gas or fluids acting upon the surface of the mercury in the chamber B. Therefore, in the following calculation for graduating the scale attarked to the tube $\mathrm{C}$, a proper allowance is made for the weight of the column of mercury.

Annexed is the investigation of a theorem for graduating the scale. The table was computed therefrom, and a scale agreeable thereto is made to be attached to an instrument which I am now making, for the purpose I have described.

\section{Calculation for the Scale.}

Ascertain nicely the capacity of the chamber A, together with the tube $\mathrm{C}$ and its ball $\mathrm{D}$, and let that quantity be denoted by $M$. Then ascertain the capacity of the tube and ball only, and denote that by $m$ : and let the ratio of these two quantities be denoted by $r$; that is $r=\frac{M}{m}$.

And let $a$ denote, in inches, the whole length of the tube C, including a length of tube equal in capacity to the ball $\mathbf{D}$; and let $x$ represent the height, in inches, of the mercury in the tube $\mathrm{C}$, from the bottom of the tube at $a$. Then when the mercury just reaches the bottom of the tube at $a$, it is plain that the pressure must be equal to $r$ atmospheres. And when the height of the mercury in the tube is equal $x$, then the pressure on the inclosed air will be equal $\frac{a}{a-x} \times r$ atmospheres.

But in order to ascertain exactly the force of the gas acting. upon the surface of the mercury in the chamber $B$, we must add to the above the weight of the column of mercury above the level in the said chamber $B$. Let $b$ denote the number of inches that $a$, the bottom of the tube, is above the level of the mercury; and let $c$ represent the height of a column of mercury equal in weight to one atmosphere, say 29.5 inches. Then the weight of the column of mercury in the tube $\mathbf{C}$ will be $=\frac{x+b}{\mathrm{C}}$. Therefore putting $y$ equal the required number of atmospheres, we shall have

$$
\begin{gathered}
\frac{a}{a-x} \times r+\frac{x+b}{c}=y . \quad \text { Or, } \\
x=\frac{a+c y-b}{2} \pm \sqrt{\frac{a+c y-b}{4}+c a r+a b-a c y .}
\end{gathered}
$$

Now put $r$ the ratio $=20^{\circ}$ and $a=76 \cdot 8$, the whole length of the tube including the ball at top; and put $c=29 \cdot 5=$ the 
$40 \mathrm{Mr}$. A. H. Haworth on some new Cacti and Mammillariz.

height of a column of mercury that will balance the pressure of the atmosphere; and put $b=7 \cdot 3$. Thus, if these values be substituted in the equation No. 2 , and different values taken for $y$, we shall thereby obtain the corresponding values of $x$, or the height of the column of mercury in the tube $\mathrm{C}$, indicating the several pressures. Thus, put $y=30$ atmospheres; then

$$
\begin{aligned}
& x=477 \cdot 25-\sqrt{227767 \cdot 5+45312+560} \cdot 64-67968 \\
& x=23 \cdot 74 \text { inches. }
\end{aligned}
$$

That is, the altitude of the mercury in the tube will be 23.74 inches, when the pressure is equal to 30 atmospheres pressing upon the surface of the mercury in the lower chamber $B$. And in this manner have been computed the different values of $x$, corresponding to different pressures, as shown in the following table:

\begin{tabular}{|c|c|c|c|c|}
\hline Pressure. & $\begin{array}{l}\text { Values of } x \\
\text { or height of } \\
\text { the mercury. }\end{array}$ & & ressure. & $\begin{array}{l}\text { Values of } x \\
\text { or height of } \\
\text { the mercury. }\end{array}$ \\
\hline 21 atmospher & res 2.49 inches. & 31 & nospheres & 25.42 inches. \\
\hline ditto & $5 \cdot 57$ & 32 & ditto & $26 \cdot 99$ \\
\hline ditto & $8 \cdot 43$ & 33 & ditto & $28 \cdot 48$ \\
\hline ditto & $11 \cdot 10$ & 34 & ditto & $29 \cdot 89$ \\
\hline ditto & $13 \cdot 57$ & 35 & ditto & $31 \cdot 21$ \\
\hline ditto & $15 \cdot 88$ & 36 & ditto & $32 \cdot 48$ \\
\hline ditto & $18 \cdot 04$ & 37 & ditto & $33 \cdot 67$ \\
\hline ditto & $20 \cdot 07$ & 38 & ditto & $34 \cdot 80$ \\
\hline ditto & $21 \cdot 96$ & 39 & ditto & $35 \cdot 88$ \\
\hline ditto & $23 \cdot 74$ & 40 & ditto & $36 \cdot 91$ \\
\hline
\end{tabular}

\section{Table for graduating the Scale.}

VIII. Descriptions of some new Cacti and Mammillariæ, recently brought from Mexico by Mr. BuLlock of the Egyptian Hall, Piccadilly; and now preserved, with many other very rare Plants, in the Nursery of Mr. Tate, in Sloanestreet. By A. H. Haworth, Esq. F.L.S. \& c.

To the Editors of the Philosophical Magazine and Journal.

Gentlemen,

A LLOW me to transmit to you herewith technical descriptions of some new and very remarkable plants of the family of Cacti Juss., which I hope you will admit into an early Number of your valuable Miscellany. And I remain

Your most obedient servant,

Queen's Elm, Chelsea, Nov. 1823.

A. H. Haworth.

CACTI 